Article

\title{
A Comparison Method for 3D Laser Point Clouds in Displacement Change Detection for Arch Dams
}

\author{
Yijing Li, Ping Liu, Huokun Li * and Faming Huang
}

Citation: Li, Y.; Liu, P.; Li, H.; Huang, F. A Comparison Method for 3D Laser Point Clouds in Displacement Change Detection for Arch Dams. ISPRS Int. J. Geo-Inf. 2021, 10, 184. https://doi.org/10.3390/ijgi10030184

Academic Editor: Wolfgang Kainz

Received: 29 January 2021

Accepted: 18 March 2021

Published: 20 March 2021

Publisher's Note: MDPI stays neutral with regard to jurisdictional claims in published maps and institutional affiliations.

Copyright: (c) 2021 by the authors. Licensee MDPI, Basel, Switzerland. This article is an open access article distributed under the terms and conditions of the Creative Commons Attribution (CC BY) license (https:/ / creativecommons.org/licenses/by/ $4.0 /)$.
School of Civil Engineering and Architecture, Nanchang University, Nanchang 330031, China; ejinn@ncu.edu.cn (Y.L.); 411116218155@email.ncu.edu.cn (P.L.); faminghuang@ncu.edu.cn (F.H.)

* Correspondence: lihuokun@ncu.edu.cn; Tel.: +86-135-7697-5537

Abstract: Dam deformation monitoring can directly identify the safe operation state of a dam in advance, which plays an important role in dam safety management. Three-dimensional (3D) terrestrial laser scanning technology is widely used in the field of deformation monitoring due to its fast, complete, and high-density 3D data acquisition capabilities. However, 3D point clouds are characterized by rough surfaces, discrete distributions, which affect the accuracy of deformation analysis of two states data. In addition, it is impossible to directly extract the correspondence points from an irregularly distributed point cloud to unify the coordinates of the two states' data, and the correspondence lines and planes are often difficult to obtain in the natural environment. To solve the above problems, this paper studies a displacement change detection method for arch dams based on two-step point cloud registration and contour model comparison method. In the environment around a dam, the stable rock is used as the correspondence element to improve the registration accuracy, and a two-step registration method from rough to fine using the iterative closest point algorithm is present to describe the coordinate unification of the two states' data without control network and target. Then, to analyze the displacement variation of an arch dam surface in two states and improve the accuracy of comparing the two surfaces without being affected by the roughness of the point cloud, the contour model fitting the point clouds is used to compare the change in distance between models. Finally, the method of this paper is applied to the Xiahuikeng Arch Dam, and the displacement changes of the entire dam in different periods are visualized by comparing with the existing methods. The results show that the displacement change in the middle area of the dam is generally greater than that of the two banks, increasing with the increase in elevation, which is consistent with the displacement change behavior of the arch dam during operation and can reach millimeter-level accuracy.

Keywords: dam displacement change detection; 3D laser point cloud; points cloud processing; point clouds comparison

\section{Introduction}

Dam safety is required to protect people's lives and the social benefits produced by dams. Deformation monitoring by comparing measured data during different periods describes the operational state of the dam in advance and intuitively, and plays an important role in scientific deformation prediction and safe operation judgment during the construction, operation, and management of the dam. In recent decades, many monitoring instruments have used appropriate methods to assess the status and safety of dams and other facilities [1-5]. Dam surface displacement is the primary metric of dam monitoring, and traditional monitoring methods (e.g., total station [6,7] and GPS [8-10]) primarily use single-point measurement modes, which use multiple monitoring points on the dam surface. These limited monitoring points cannot fully describe the deformation of the entire structure. Compared to the traditional single-point measurement modes, terrestrial laser scanning (TLS) and ground-based interferometric synthetic aperture radar (GB InSAR) [11,12] have the characteristics of non-contact and surface measurement. GB-InSAR 
collects two-dimensional images and implements deformation monitoring through processing steps such as image registration, phase unwrapping, estimation of the atmospheric phase component, and displacement computation and geocoding. However, there is no reliable atmospheric phase correction model, and the shorter radar wavelength increases the difficulty of phase unwrapping, all of which affects the accuracy of GB InSAR data processing [13-16]. TLS technology can efficiently measure spatial data, describe an object's surface across large areas, and produce high-density, high-resolution large 3D point clouds of the object more directly, quickly, and accurately. Compared to GB InSAR, the data collected by TLS are more visualized and easier to process. TLS is widely used in all types of topographic surveys [17-21], landslide monitoring [22-25], deformation monitoring [26-29], and surface reconstruction [30,31], and provides a new method for measurement work in water-conservancy projects' construction, operation, and management. Extracting dam displacement information from TLS data is a challenging and important task that is critical to displacement detection using TLS technology [1,32-36]. Wan [37] monitored the extrusion sidewall of concrete-faced rockfill dam based on TLS by drawing the displacement field model. However, this field model was a contour line and lacked intuitiveness. Guo [38] used TLS to monitor the settlement of the dam in the mining area and selected 50 points at equal intervals along the strike of the dam to analyze the deformation. However, these sampling points at equal intervals were unable to fully represent the entire deformation of the dam. Wang [39] proposed an earth-rock dam deformation monitoring method based on 3D laser scanning technology, and the cross-section point cloud data series at the same location collected at different times were compared and analyzed to figure out the dam deformation. However, the cross section did not reflect the entire deformation of the dam surface. The above studies have verified the feasibility of the application of 3D laser scanning technology to dam deformation monitoring, but they have not fully utilized the dense point cloud to describe the overall deformation of the dam. Using the two-phase point cloud comparison to make a dam surface deformation cloud map can intuitively and completely show the dam deformation distribution.

Since deformation monitoring must compare different periods of data in the same coordinate system, data registration is a key component of point cloud processing. However, there are no corresponding points in the discrete point cloud collected by the 3D laser scanner, which yields difficulties in data registration. To ensure the accuracy of the point cloud registration and the quality of the deformation analysis, many studies have set up high-precision control networks and used total stations or GPS and other measuring equipment for joint observations in fieldwork [40-46]. However, this method requires more time for fieldwork and increases costs. Manual target setting is an efficient method for point cloud registration [47-50]. However, to collect data in different periods, the target must be fixed for a long time, which is difficult to accomplish in the natural environment of the dam area. Many studies have fitted straight lines and planes with corresponding geometric elements from point clouds to solve these problems [51,52]. However, for dam deformation monitoring, the stable areas used for registration, such as the bedrock on both sides of the dam and the ground downstream, often lack linear and plane elements. The iterative closest point (ICP) algorithm is a classical point cloud registration method that does not require the corresponding elements [53-55] and has a high registration accuracy. However, this method easily falls into a local optimum due to the effects of the initial value and has a high computational cost. In this paper, in order to adapt the registration method to the natural scene around a dam, the stable rock mass point cloud in front of the dam is used to replace the manual target and other corresponding elements to improve the registration accuracy. Via two-step rough-fine ICP registration, the data of the two periods are efficiently, quickly, and accurately incorporated into the unified coordinate system from rough to fine.

By calculating the distance between point clouds in different periods, the deformation of the dam surface can be analyzed comprehensively. Compared to the high level of maturity reached by instruments, solutions to perform point cloud comparison in $3 \mathrm{D}$ are 
scarce and hardly adapted to complex natural surfaces [56]. When the point cloud scene is a relatively flat surface, the most commonly used point cloud comparison method is the deformation compared to the digital elevation model (DEM) [7,57-59]. This method interpolates two periods of point clouds into the DEM and then measures the distance of two DEMs in the vertical direction pixel by pixel. The calculation is small and fast but is not suitable for engineering buildings with large surface changes. Additionally, due to the missing holes in the point cloud or the sparse point density caused by the scanning angle or occlusion, DEM interpolation with a fixed resolution will reduce the accuracy of the comparison. A point cloud comparison method called point cloud to point cloud (C2C) is used to perform deformation analysis by calculating the distance between adjacent points in two sets of point cloud data. Girardeau-Montaut [60] introduced several simple C2C comparison techniques and improved the best-performance method using a Hausdorff distance calculation. The $\mathrm{C} 2 \mathrm{C}$ method does not require model building or DEM interpolation for point cloud data, nor must it calculate the surface normal; thus, the $\mathrm{C} 2 \mathrm{C}$ method is the most efficient and simplest method in point cloud deformation analysis. However, the distance measured by this method is sensitive to the roughness, outliers, and point spacing of point clouds; thus, it is primarily applied to measure rapid changes in dense point clouds rather than to provide accurate distance measurements. The point cloud comparison based on point-to-model comparison calculates the distance between a group of point cloud data and another group of reference models instead of the distance between point clouds; thus, this method can effectively reduce the influence of point cloud roughness on a comparison accuracy. Xu [61] developed a high-precision NURBS surface reference model of earth rock dams, compared the difference between the point clouds of earth rock dams in different periods and this reference model. However, the fitting surface may not be subtle enough to represent the surface of objects with the large curvatures where large errors are likely to be induced, and the construction of the dam surface with four procedures is also time consuming and complicated. Monserrat [62] estimated the deformation parameters by local surface matchings and the validation results achieved on the simulation experiment and landslide test site. Rinske [63] and Xie [64] fitted the point cloud to a cylindrical model to detect the deformation in the tunnel. M.Alba [65] analyzed dam deformation by calculating the distance between points to mesh, which are triangular or polynomial surfaces interpolated from resampled point clouds. However, creating a surface mesh is complex for point clouds with significant roughness at all scales or missing data due to occlusion [56]. Therefore, for the surface of complex structures or large curvatures, the DEM-based comparison is not suitable for overhanging parts, and the fixed resolution limits the details of the original data, whereas the point-tosurface model comparison overcomes the roughness well under a fixed fitting scale; in the point-to-surface model, however, it is more difficult to choose the appropriate scale and model to fit the surface and overcome the roughness of the point cloud. In order to solve the above problems and reduce the impact of point cloud roughness on the comparison accuracy more effectively, a dam contour model is designed in this study to describe the distance comparison. The line model that replaces the surface model is simpler to construct, more flexible, and more suitable for arch dams.

In this study, the processing method of 3D laser point cloud data in arch-dam deformation monitoring is investigated. A two-step registration method, based on the rock mass in front of the dam, and a point cloud comparison method, based on the contour model, are proposed. Lastly, this study analyzes the overall displacement variation of the dam surface between two states of point cloud data.

\section{Methodology}

Dam displacement monitoring based on TLS is able to fully describe the displacement changes on the dam surface. In order to improve the accuracy and efficiency of the registration, and apply it to the natural scene around the dam, the complete point clouds and rock mass point clouds of the second status are incorporated into the first phase's 
coordinate system via rough to fine registrations by the ICP algorithm. Then, the model-tomodel distance calculation and dam surface displacement variation analysis are described using contour model construction and curve fitting in order to eliminate the influence of point cloud roughness on the comparison accuracy. The flow chart describing this process is shown in Figure 1.

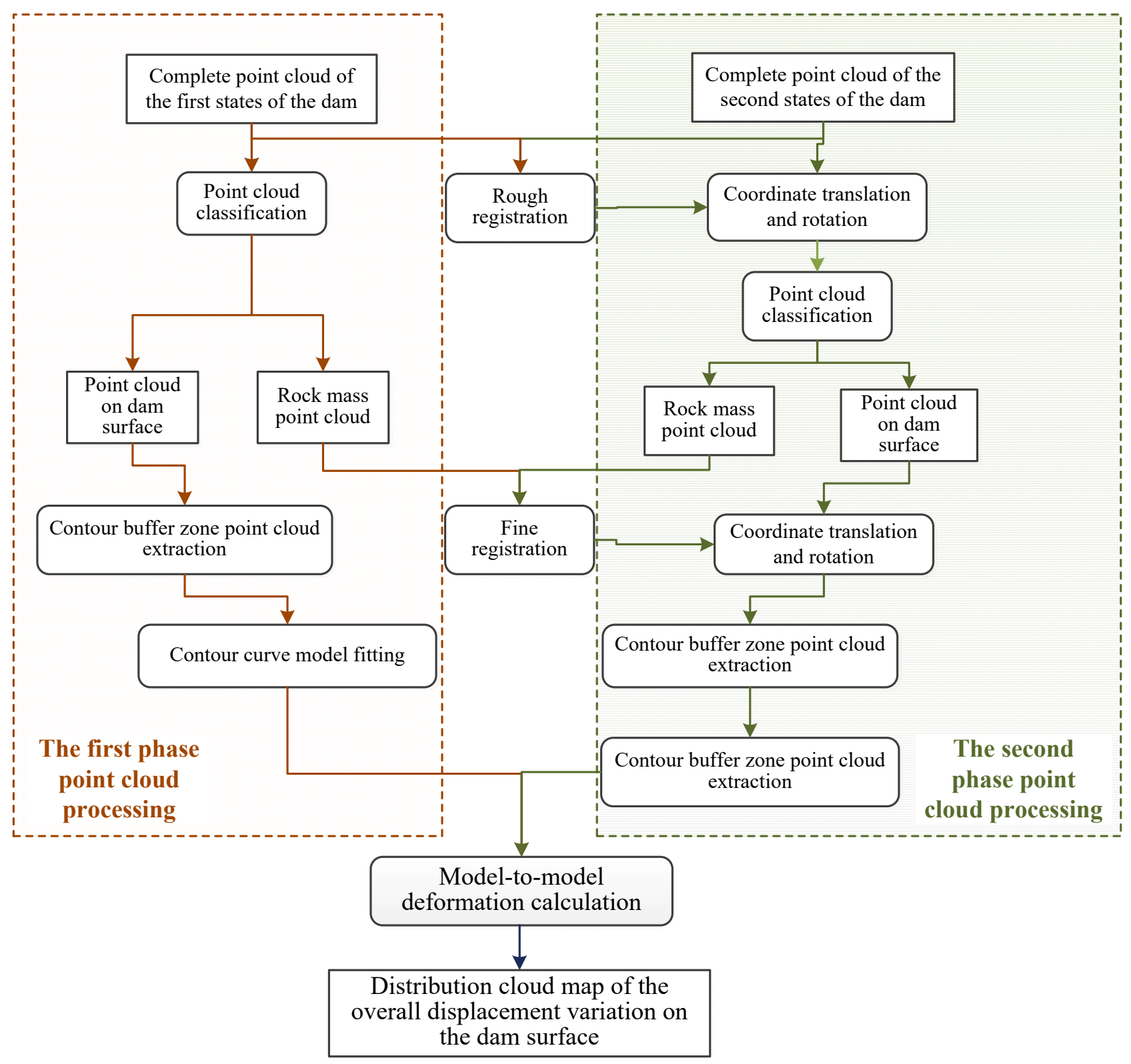

Figure 1. Flow chart of dam displacement variation analysis based on the 3D point cloud.

\subsection{Registration}

The point cloud data of the two states of the dam come from different collection times and station locations. To compare the deformation of the dam surface, the point cloud registration of the two states should be performed first. The registration of point clouds in different periods is an important part of dam deformation monitoring, and the accuracy of registration directly affects the results of the deformation analysis. The corresponding points cannot be directly obtained from the discrete and irregular point cloud for registration, and the dam surface is the monitoring object of the unstable structure; thus, it is not suitable to extract the registration elements, and it is more difficult to detect 
the corresponding line or plane in the natural environment of the dam area. Therefore, the stable rock mass in front of and on both sides of the dam is selected as the registration element, and the two-phase coordinate transformation parameters are calculated by the ICP algorithm from rough to fine. In the rough registration, the initial value is given manually, and the complete point clouds of two states are automatically registered by the ICP algorithm. Then, the point cloud of the dam surface and rock mass are manually classified. Finally, the rough registration result is used as the initial value to perform secondary automatic fine registration on the rock mass point clouds.

\subsubsection{Rough Registration}

The ICP algorithm is used for rock mass registration, which leads the result to fall into the local optimum, thereby reducing the accuracy of registration. Therefore, the first rough registration is performed for the complete point clouds of two phases, and the translation and rotation parameters of the second phase point cloud coordinates are calculated with the first phase point cloud coordinates as the reference. By setting the initial value manually, reducing the standard deviation accuracy of the ICP algorithm, and optimizing the sampling points, the operation efficiency can be improved. The entire point cloud includes non-dam surface points, such as vegetation in front of dams, surrounding mountains, rock masses, and workers. Unstable objects, such as a large amount of vegetation and walking people, will seriously interfere with the registration accuracy of point clouds. Therefore, the first rough registration should be considered as the initial value, and then the second fine registration based on the stable rock mass should be performed for the point cloud data used to analyze the fine deformation of the dam.

\subsubsection{Fine Registration}

Based on the distribution distance of the point cloud, the entire point cloud collected by the survey station is segmented using the connected component labeling method. The extracted point clouds of the dam surface and rock mass are used for deformation analysis and fine registration, respectively. Vegetation and rock mass show marked differences in the surface change rate $S V_{p i}$, surface density $S D_{p i}$, and flatness Planarity p $_{i}$ of the point clouds, as shown in Table 1 . These three characteristic values can be used to roughly classify the rock mass point cloud using simple thresholds. However, to ensure the registration accuracy of the rock mass' point cloud, a small amount of vegetation on the surface of the rock mass must be manually removed.

Third, the ICP algorithm is used for the second high-precision registration of the rock point cloud to obtain the final coordinate transformation parameters. Taking the coordinate transformation result of a rough registration as the initial value, only iterating the ICP algorithm on the rock point cloud can make the result converge quickly. By filtering out the interference point cloud and setting a smaller standard deviation, the registration accuracy can be improved. Affected by the location of the station, the greater the distance difference between the two stations is, the greater the change in the scanning angle, the greater the difference between the density and integrity of the rock point cloud, and the greater the corresponding decrease in the point cloud registration accuracy. Therefore, the two stations should be near each other during data acquisition. Additionally, to ensure the accuracy of the registration, many large, symmetrical, uniform, and stable rocks should be selected in the dam environment for secondary fine registration. 
Table 1. Point cloud feature description of several rock masses and vegetation.

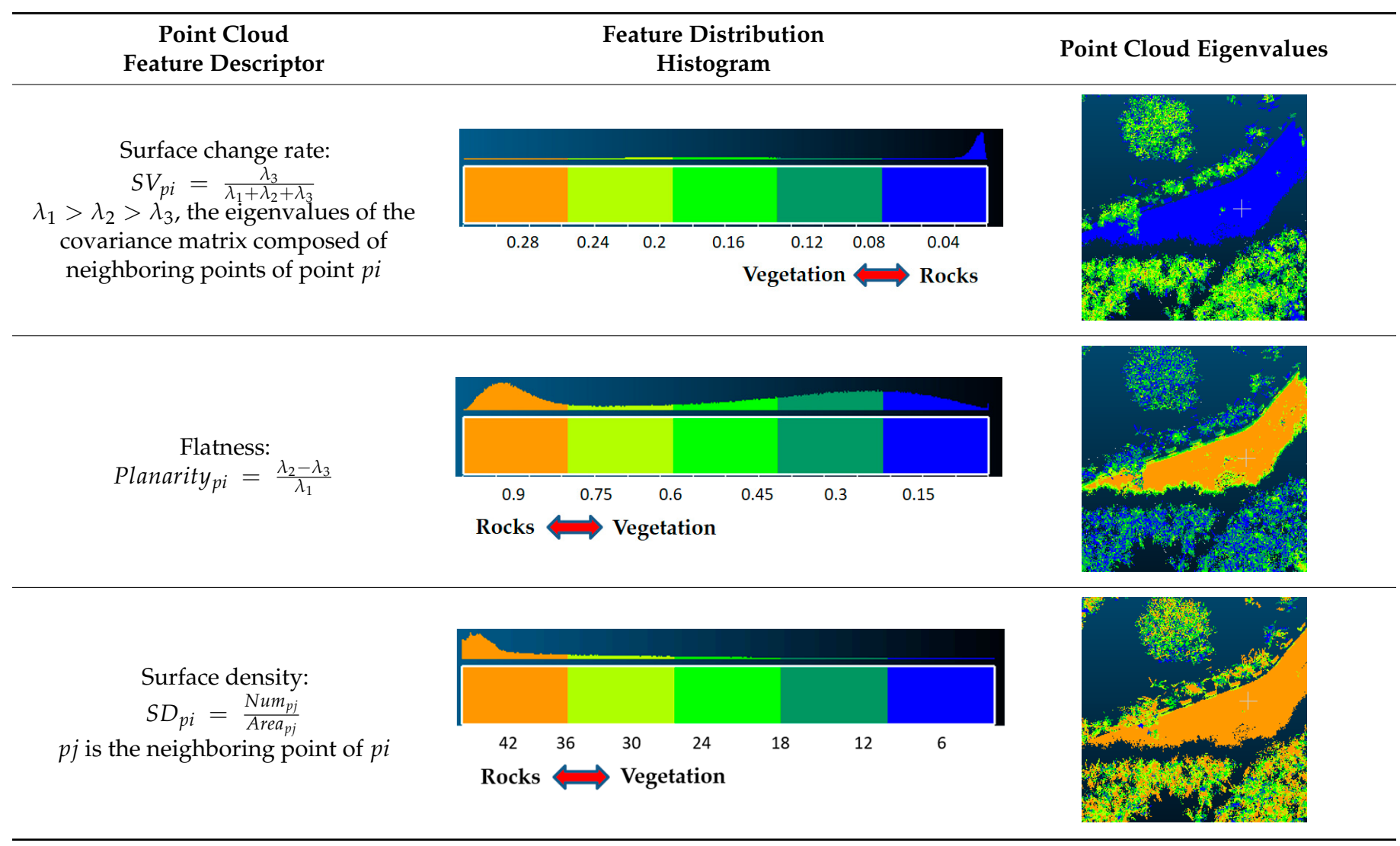

\subsection{Methods of Point Cloud Comparison}

Since an arch dam is a highly statically indeterminate shell structure constrained by rock masses on three sides, the arch dam transmits most of the reservoir's water pressure to the rock mass on both sides of the dam end in the form of horizontal thrust, and a small part of the load is transferred to the foundation as a cantilevered beam. These phenomena show that the displacements of the arch end and dam foundation are small; thus, deformation monitoring is primarily used to compare the radial displacement of the arch dam along the flow direction. The radial displacement of the entire dam can be obtained by comparing the distance between the two-phase point clouds after registration. However, due to the limitation of laser scanning equipment, the inevitable roughness of the point cloud directly affects the accuracy of the distance comparison. The influence of roughness on comparison results can be weakened by modeling the contour buffer zone of the point cloud on the dam surface and then calculating the distance between the models.

\subsubsection{Construction of Contour Model}

Due to the irregular discrete distribution characteristics of the point cloud, a contour buffer zone is developed for any elevation value $Z a$ to better fit the contour curve model. As shown in Figure 2a, the buffer zone radius $\Delta z$ should be marginally above the point cloud density. Then, the point cloud in the buffer zone is projected along the $Z$ axis to the $Z=Z a$ projection plane to form a two-dimensional contour point cloud, as shown in Figure $2 b$.

Since the extracted contour point cloud cannot be guaranteed to fit on a parameter curve completely, this is also caused by the roughness of the point cloud and other interference point clouds. In order to improve the accuracy of curve fitting, a random sampling consensus algorithm (RANSAC) is used to remove some large outliers. Then, The least square method is used to fit the contour point cloud to a curve to establish the contour 
curve model. As there is no design function for the arch ring on the downstream surface of most arch dams, particularly the design curves of hyperbolic arch dams, the left, and right arches are inconsistent. To build an accurate contour model, partial curve model fitting of the contour point clouds of the two states of the dam surface is performed, as shown in Figure 3a. Among them, the RANSAC algorithm and the least square method can be implemented well on the MATLAB platform, and the algorithm can be automatically calculated after the program is written.

\subsubsection{Dam Displacement Variation}

After fitting and optimizing the contour point cloud model, taking the first phase data as a reference, the distance between the interpolation points on the second phase contour model and the first phase contour model is compared under the corresponding elevation to describe the calculation of dam surface displacement variation. As shown in Figure 3b, the shortest distance $d_{\min }$ from the interpolation point $Q$ of the second phase contour to the first phase model curve is the distance between the two models at this position (the details were specified in reference [66]). By calculating the shortest distance from all the interpolation points of the second-stage model to the first-stage model, the displacement distribution of the two dam surfaces at the same elevation can be obtained. As shown in Figure $3 \mathrm{a}, \mathrm{b}$, there is a large error between a comparison distance $d_{c 2 c}$ based on the nearest point and the real distance $d$ of the two groups of data in the point cloud with a large roughness, while the distance $d_{\min }$ between the contour models is not affected by the roughness of the point cloud, which can more accurately describe the displacement variation of the dam surface.

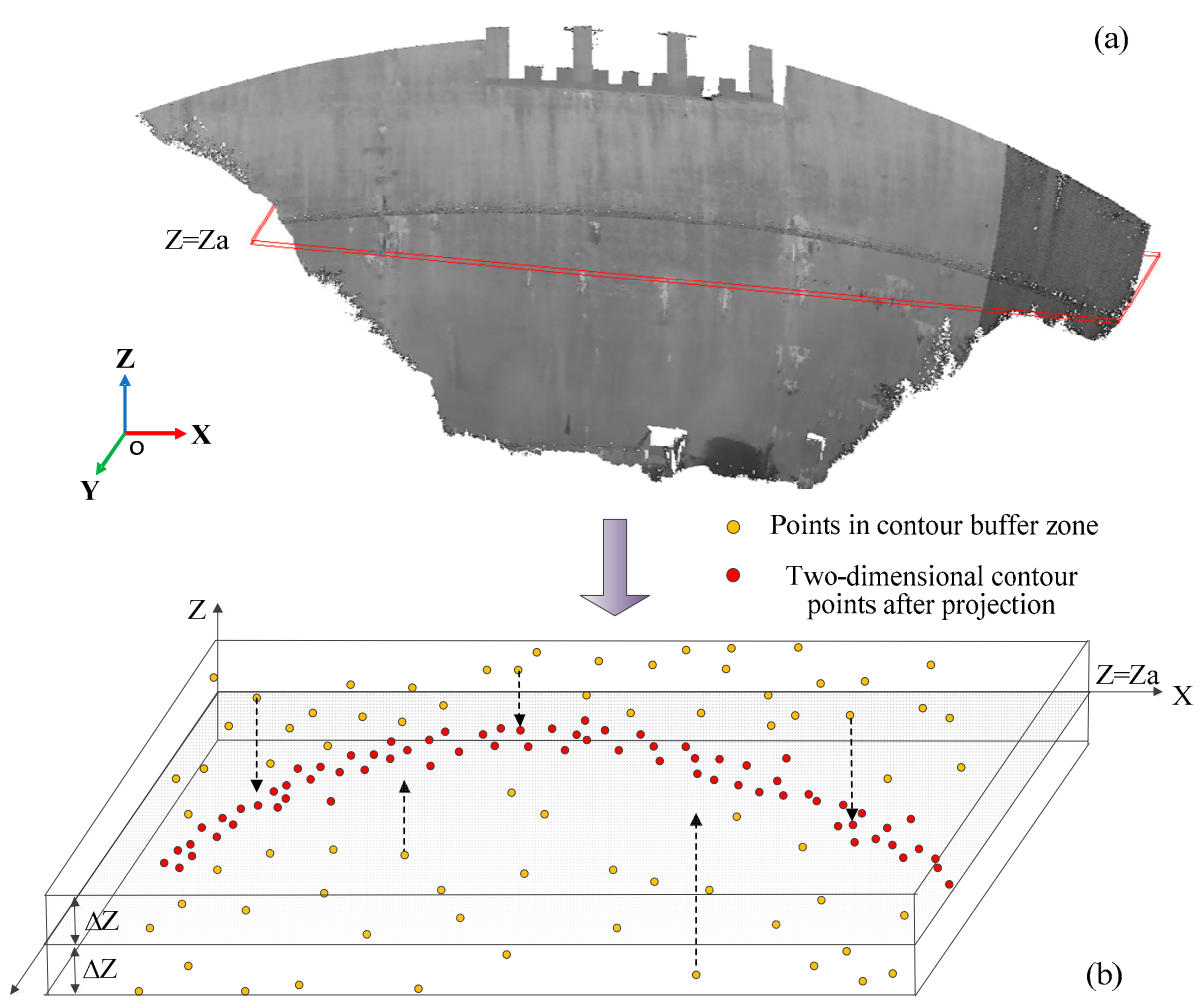

Figure 2. Contour point cloud extraction. (a) Extracting point cloud buffer and (b) extracting contour point cloud. 


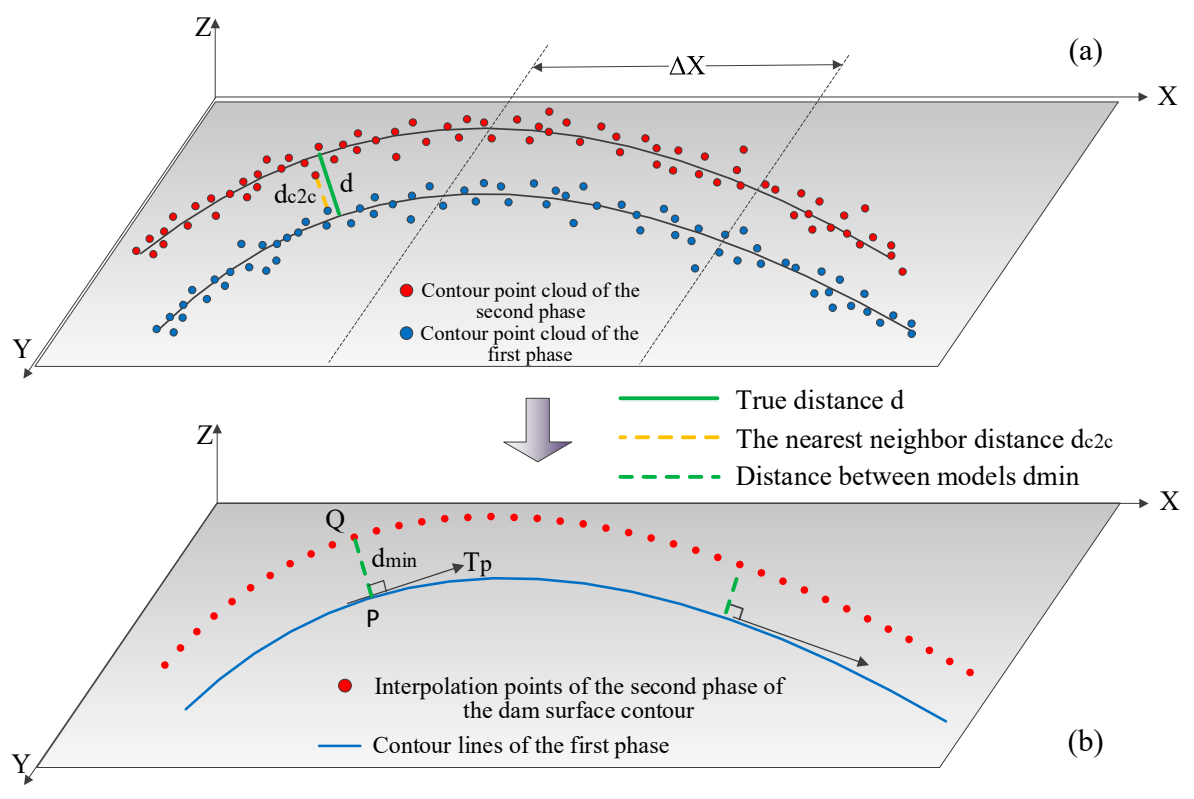

Figure 3. Local curve fitting and model distance comparison. (a) Piecewise curve fitting and (b) model-to-model distance comparison.

\section{Materials}

The Xiahuikeng Reservoir is located on Huating Water, a secondary tributary of the Xinjiang River in Huating Township, Shangrao County, Jiangxi Province, China at $118^{\circ} 09^{\prime} \sim 118^{\circ} 11^{\prime}$ east longitude and $28^{\circ} 11^{\prime} \sim 28^{\circ} 15^{\prime}$ north latitude. The reservoir is a mediumsized water conservancy project that focuses on power generation and considers the comprehensive use of irrigation, flood control, and aquaculture. The primary buildings of the project include dams, power generation and water diversion systems, ground-mounted powerhouses, and booster stations. The control basin area of the dam site is $106.7 \mathrm{~km}^{2}$, the annual average flow is $4.54 \mathrm{~m}^{3} / \mathrm{s}$, the normal storage level of the reservoir is $421.0 \mathrm{~m}$, the design flood level is $423.02 \mathrm{~m}(\mathrm{P}=2 \%)$, and the check flood level is $423.46 \mathrm{~m}(\mathrm{P}=0.2 \%)$. When the total storage capacity of the reservoir is $0.35 \times 108 \mathrm{~m}^{3}$, the installed capacity of the power station is $2 \times 8000 \mathrm{KW}$. The Xiahuikeng Arch Dam, as shown in Figure 4a, is a mortar-masonry double-curvature arch dam. The dam crest elevation is $423.5 \mathrm{~m}$, the maximum dam height is $102.39 \mathrm{~m}$, the arch thickness-to-height ratio is 0.2 , the dam crest is $4.5 \mathrm{~m}$ wide, the crest center arc length is $247.4 \mathrm{~m}$, the horizontal arch ring line type is a unified quadratic curve, and the maximum dam height is $102.4 \mathrm{~m}$. The spillway of the reservoir is arranged on the top of the dam with three holes, each with a net width of $10 \mathrm{~m}$, and the top elevation of the weir is $416.0 \mathrm{~m}$, which is controlled by an open-top curved steel gate. The gate has a normal water retention depth of $5.0 \mathrm{~m}$ and uses jet energy dissipation.

The experiment takes the arch dam as the object and uses a Trimble TX8 ground 3D laser scanning device to collect two-phase point cloud data on the dam surface. The water levels of the dam during the two phases of data collection were $410.5 \mathrm{~m}$ and $396.25 \mathrm{~m}$, respectively, with a difference of $14.25 \mathrm{~m}$. This difference is the largest water level difference of the Xiahuikeng Dam and is suitable for the measurement and research of dam displacement changes.

To avoid the effect of splicing errors of multiple stations on the accuracy of deformation analysis, we collected eight sets of data at different locations downstream of the dam in two periods. In order to obtain more complete dam surface data, two sets of data in different periods were selected for experimentation. Since the farther the instrument is from the dam, the greater the distance error, and the standard maximum measurement distance of Trimble TX8 is $120 \mathrm{~m}$; therefore, the selected two sets of data collection stations are about $80 \mathrm{~m}$ away from the dam. Figure $4 \mathrm{~b}$ shows these two sets of complete point clouds, 
in which the blue-green point cloud is the data collected in the first phase, and the pink-red point cloud is the data collected in the second phase.

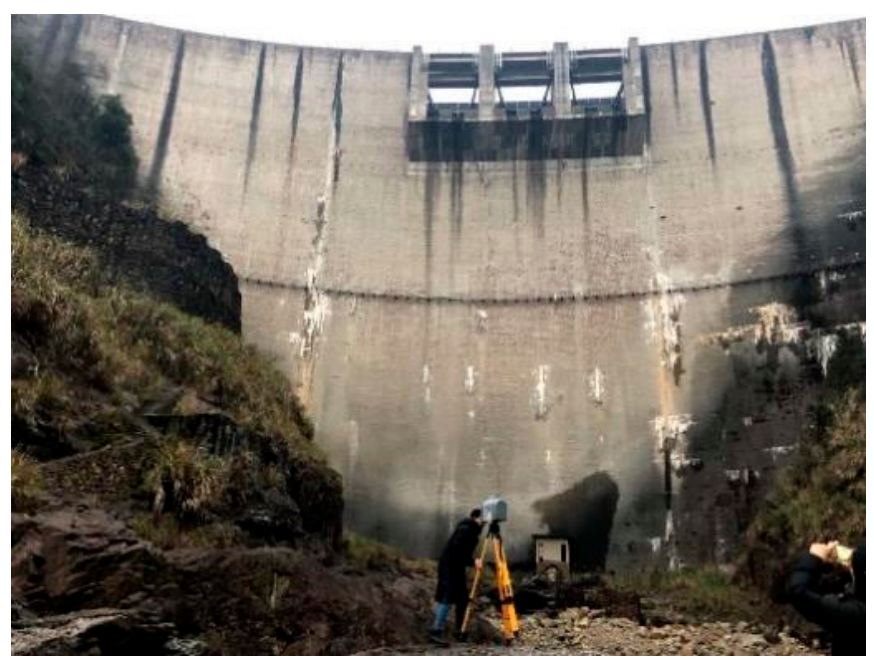

(a)

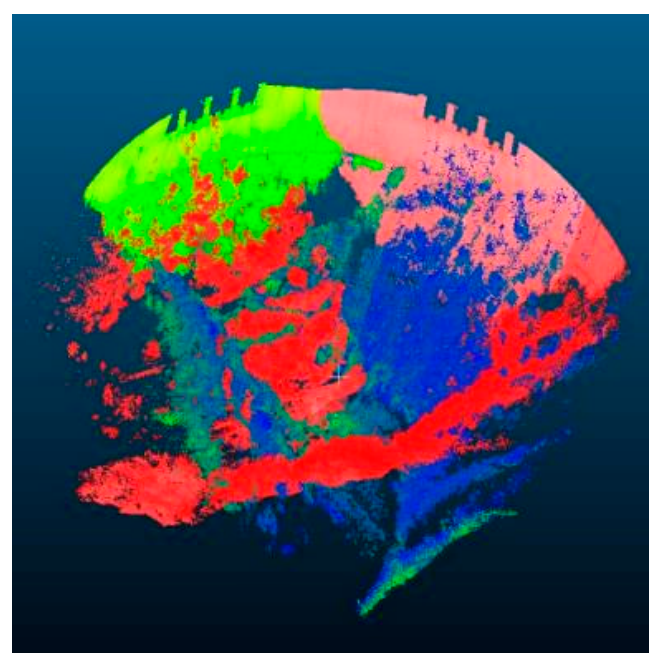

(b)

Figure 4. (a) Xiahuikeng Arch Dam and (b) two-phase point cloud used in the experiment.

\section{Results}

\subsection{Two-Phase Point Cloud Registration}

The coordinate conversion matrix of the two-phase point cloud is solved by the twostage registration method based on the rock mass. The conversion matrix is shown in formula (1) as follows:

$$
R=\left[\begin{array}{cccc}
\cos \beta \cos \alpha & \cos \beta \sin \gamma & -\sin \beta & \Delta x \\
-\cos \alpha \sin \gamma+\sin \alpha \sin \gamma \cos \gamma & \cos \alpha \cos \gamma+\sin \alpha \sin \beta \sin \gamma & \sin \alpha \cos \beta & \Delta y \\
\sin \alpha \sin \gamma+\cos \alpha \sin \beta \cos \gamma & -\sin \alpha \cos \gamma+\cos \alpha \sin \beta \sin \gamma & \cos \alpha \cos \beta & \Delta z \\
0 & 0 & 0 & 1
\end{array}\right]
$$

where $\alpha, \beta, \gamma$ are the rotation angles of the three coordinate axes, and $\Delta x, \Delta y, \Delta z$ are the translation parameters of the coordinate origin along the three coordinate axes. Taking the point cloud coordinates collected in the first phase as a reference, the first rough registration of the complete point cloud is performed, and the conversion matrix is determined, as shown in Table 2. The root mean square (RMS) refers to the root mean square of the nearest points of the two sets of point clouds after registration, and the RMS difference is the accuracy threshold of the ICP iteration. The rock mass in front of the dam (Figure 5a) is used for the second precision registration based on the rock mass to obtain the conversion matrix shown in Table 3, and the dam surface point cloud registration result is shown in Figure $5 b$. Figure $5 c-f$ shows a comparison of the point cloud of the rock mass and the dam surface before and after the second fine registration. Based on the degree of coincidence of the rock mass and the dam before and after fine registration, and the RMS value of the two registrations, fine registration based on the stable rock mass eliminates the interference of unstable point clouds, such as vegetation, and improves registration accuracy. Additionally, because the first rough registration is given a more accurate initial value, it effectively prevents the accurate registration from falling into the local optimum and quickly converges to the optimal solution, which improves the computational efficiency of the method. In Figure $5 b$, the point cloud in the red rectangular box is not completely registered due to a problem in the device's firmware during the second phase of data collection, which caused a large distance measurement error in this part of the point cloud. To prevent this error from affecting the analysis of the changes in dam displacement, this portion of the point cloud is deleted in the subsequent point cloud comparison. 


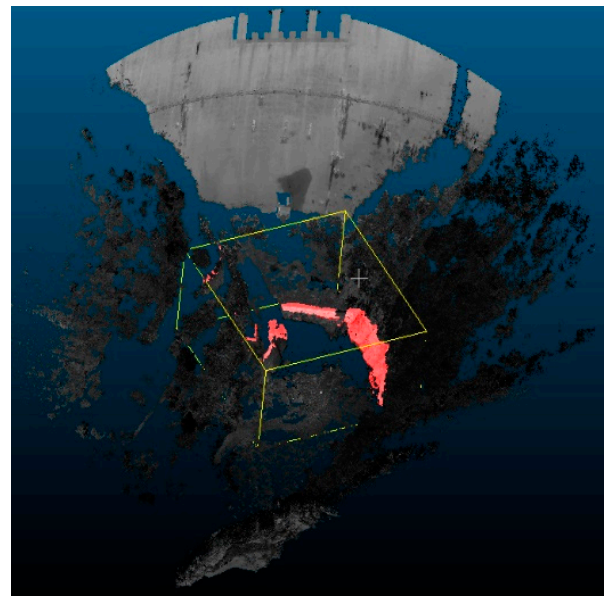

(a)

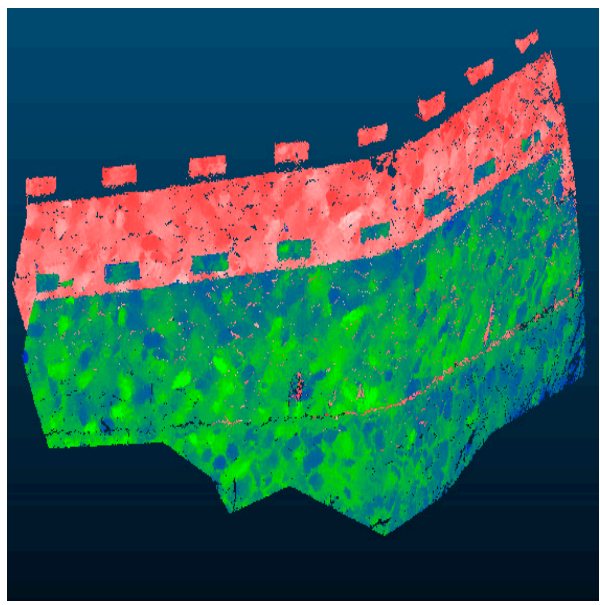

(c)

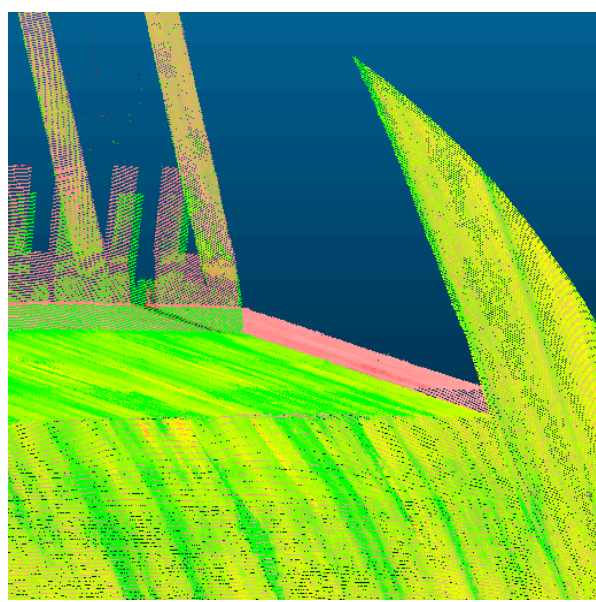

(e)

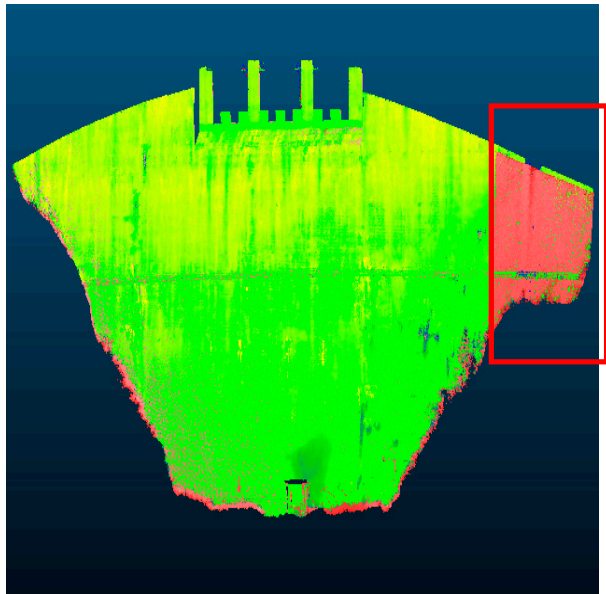

(b)

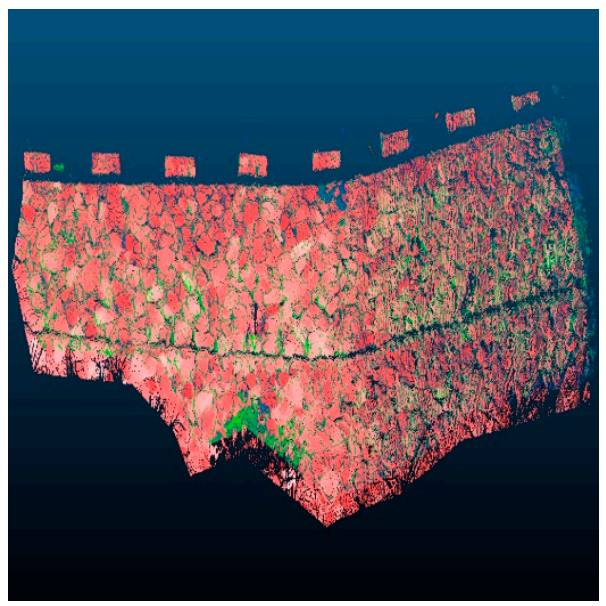

(d)

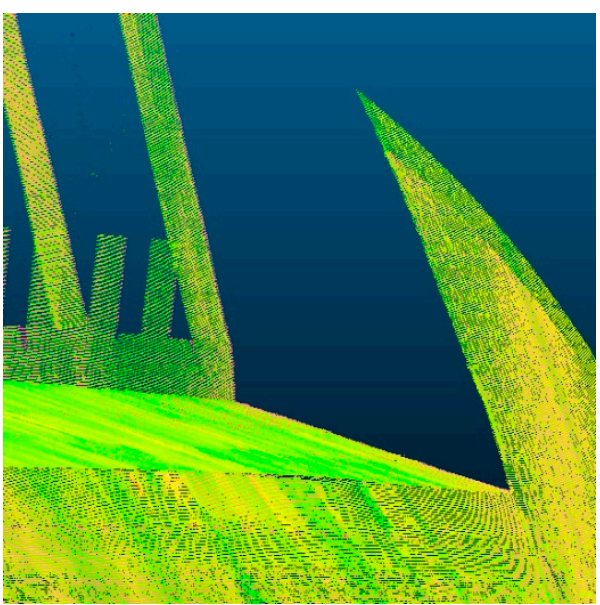

(f)

Figure 5. Two registrations based on the complete point cloud and rock mass point cloud. (a) The rock mass in front of the dam used for secondary precision registration; (b) two-stage dam surface point cloud after the second fine registration and classification; (c) two-stage rock mass point cloud for the first rough registration; (d) two-stage rock mass point cloud for the second fine registration; (e) part of the point cloud of the two dam faces after the first rough registration; and (f) part of the point cloud of the two-stage dam surface after the second fine registration. 
Table 2. Coordinate transformation matrix for the first rough registration of two complete point clouds.

\begin{tabular}{cccc}
\hline 0.996 & -0.047 & -0.070 & 3.143 \\
0.049 & 0.998 & 0.033 & 2.633 \\
0.068 & -0.036 & 0.997 & 6.071 \\
0.000 & 0.000 & 0.000 & 1.000 \\
\hline \multicolumn{2}{c}{ RMS $=0.755561 \mathrm{~m}$} & RMS Difference $=1.0 \times 10^{-5}$ \\
\hline
\end{tabular}

Table 3. Second precision registration coordinate transformation matrix of the two-phase rock mass point cloud.

\begin{tabular}{cccc}
\hline 0.999991834164 & -0.000157242248 & -0.004154545255 & 0.233834072948 \\
0.000160262105 & 1.000000000000 & 0.000726647791 & -0.141341060400 \\
0.004154435359 & -0.000727307750 & 0.999991595745 & -0.353730350733 \\
0.000000000000 & 0.000000000000 & 0.000000000000 & 1.000000000000 \\
\hline RMS $=0.00719947 \mathrm{~m}$ & \multicolumn{2}{c}{ RMS Difference $=1.0 \times 10^{-8}$} \\
\hline
\end{tabular}

\subsection{Analysis of Displacement Change}

By establishing the contour model of the point cloud of the two states and calculating the distance between the models, the analysis of the displacement change across the dam surface and any height of the two states is described. To ensure a sufficient number of point clouds in the contour buffer zone and to achieve a complete comparison of the displacement changes in the dam surface, the dam surface, and the contour buffer strips with a distance of $0.02 \mathrm{~m}$ are extracted, for a total of 3891 buffer strip data points, as shown in Figure 6.

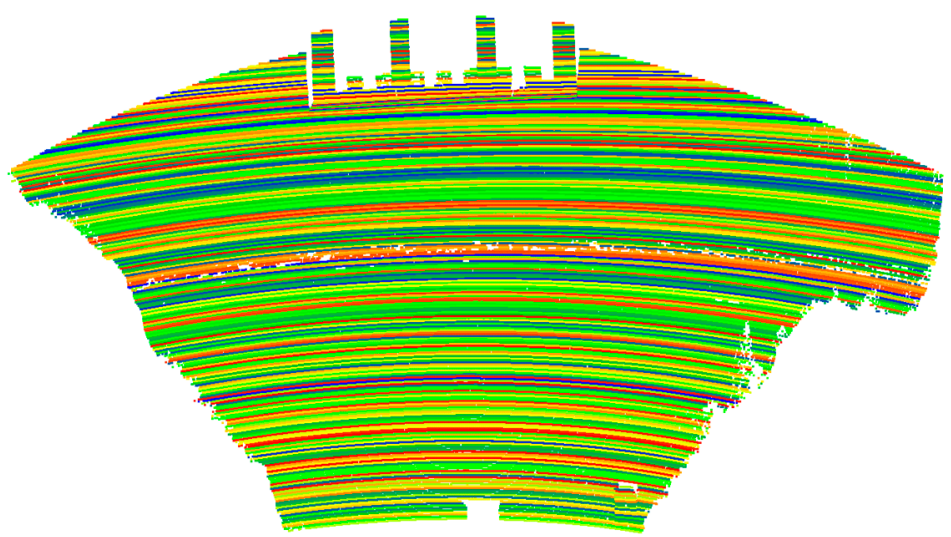

Figure 6. Color rendering of dam arch ring.

\subsubsection{Contour Model Construction and Comparison}

The construction of a local curve model for the point cloud in the buffer zone of the two-phase dam surface is now described. Three contour models were selected in the experiment, and the root mean square error (RMSE) and goodness of fit $\left(R^{2}\right)$ were used to evaluate the quality of the model and were compared to the global curve model. The formula for RMSE is as follows:

$$
\operatorname{RMSE}(x, h)=\sqrt{\frac{1}{m} \sum_{i=1}^{m}\left(h\left(x_{i}\right)-y_{i}\right)^{2}},
$$


where $h\left(x_{i}\right)$ is the optimized model data, $y_{i}$ is the contour point cloud data, and $m$ is the number of contour point clouds. The smaller the RMSE value is, the more accurate the model, and vice versa. The formula for $R^{2}$ is as follows:

$$
R^{2}=\frac{S S R}{T S S}=\frac{\sum_{i=1}^{m}\left(h\left(x_{i}\right)-\overline{y_{i}}\right)^{2}}{\sum_{i=1}^{m}\left(y_{i}-\overline{y_{i}}\right)^{2}},
$$

where SSR is the sum of squares of the difference between the model data and the mean of the original data, and TSS is the sum of squares of the difference between the original data and the mean of the original data. $R^{2}$ can also characterize model quality-the closer the calculated value is to 1 , the better the model quality. Table 4 shows the model quality evaluation results, indicating that the local curve has better model fitting quality than the global curve.

Table 4. Curve model quality evaluation result.

\begin{tabular}{ccccccc}
\hline & Local & Local & Local & Global & Global & Global \\
& Curve & Curve & Curve & Curve & Curve & $\begin{array}{c}\text { Curve } \\
\text { Curve }\end{array}$ \\
& $\mathbf{Z 1 = 6 9 . 8 8}$ & $\mathbf{Z 2 = 3 7 . 8 8}$ & $\mathbf{Z 3 = 1 9 . 8 8}$ & $\mathbf{Z 1 = 6 9 . 8 8}$ & $\mathbf{Z 2}=\mathbf{3 7 . 8 8}$ & $\mathbf{Z 3}=\mathbf{1 9 . 8 8}$ \\
& $\mathbf{m}$ & $\mathbf{m}$ & $\mathbf{m}$ & $\mathbf{m}$ & $\mathbf{m}$ & $\mathbf{m}$ \\
\hline$R M S E$ & 0.0152 & 0.0138 & 0.0121 & 0.0233 & 0.0327 & 0.0226 \\
$R^{2}$ & 1 & 1 & 1 & 0.99 & 0.99 & 0.99 \\
\hline
\end{tabular}

In the experiment, 10 two-phase contour point clouds were selected at equal intervals for model fitting and distance calculation, and local average displacement change statistics were performed on the middle and both sides of the dam surface on these 10 contours (Figure 7) to analyze the displacement changes in different positions on the dam surface. The red, green, and blue broken lines are the average displacement changes in the middle, left, and right sides of the dam, respectively. The figure shows that the displacement in the middle of the dam is above the left and right sides, and as the height increases, the overall displacement of the dam surface changes gradually increases. Figure $8 a-j$ shows the histograms of the displacement variation distribution of the 10 contour models and their calculated means-the lower the elevation is, the smaller the displacement variation and the concentrated distribution.

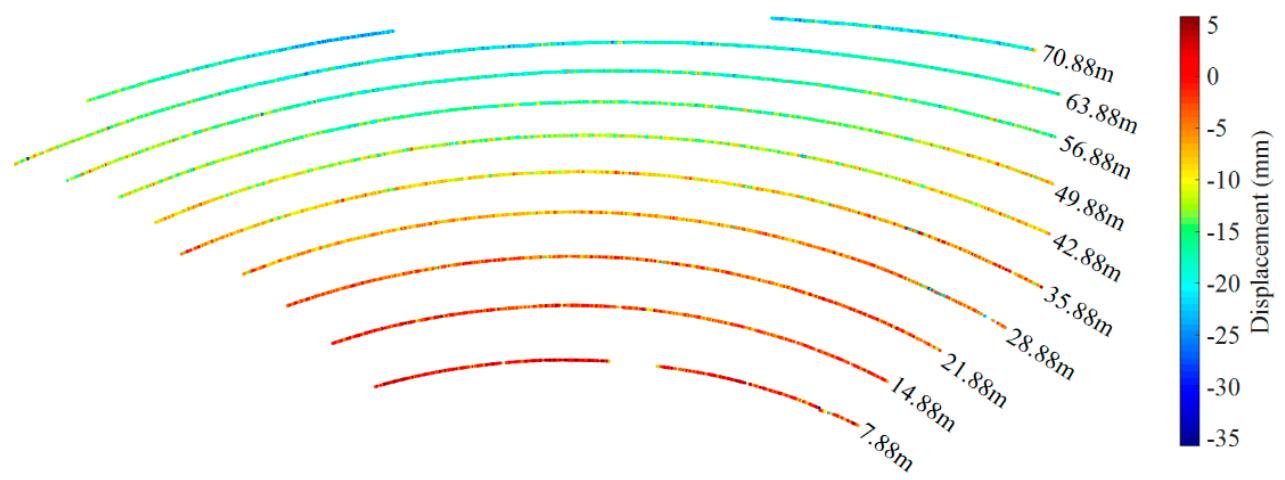

Figure 7. Displacement changes in contour lines at different elevations. 


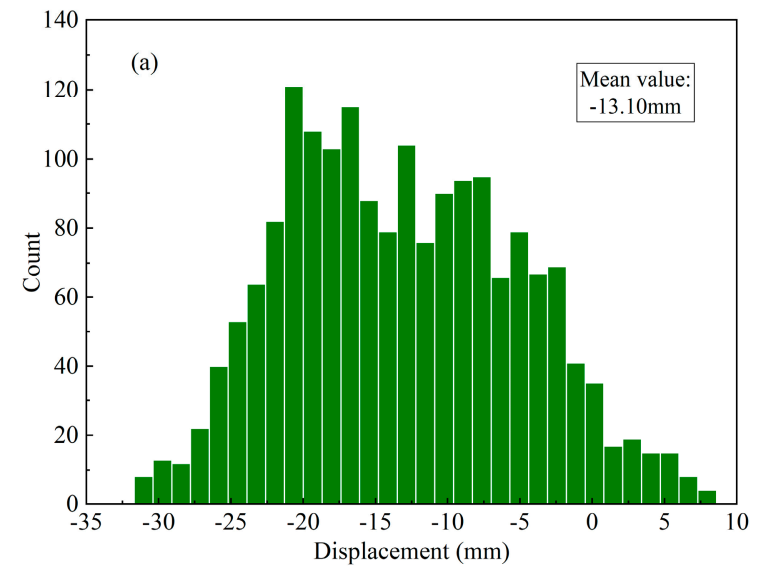

(a)

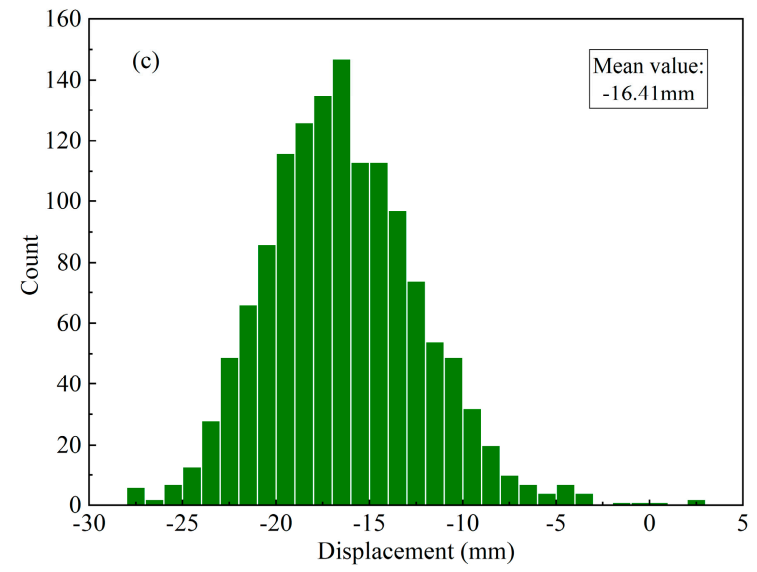

(c)

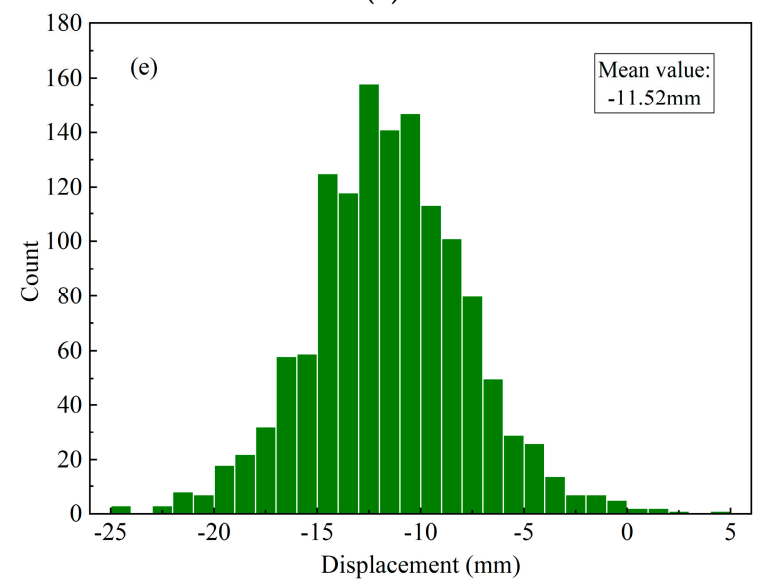

(e)

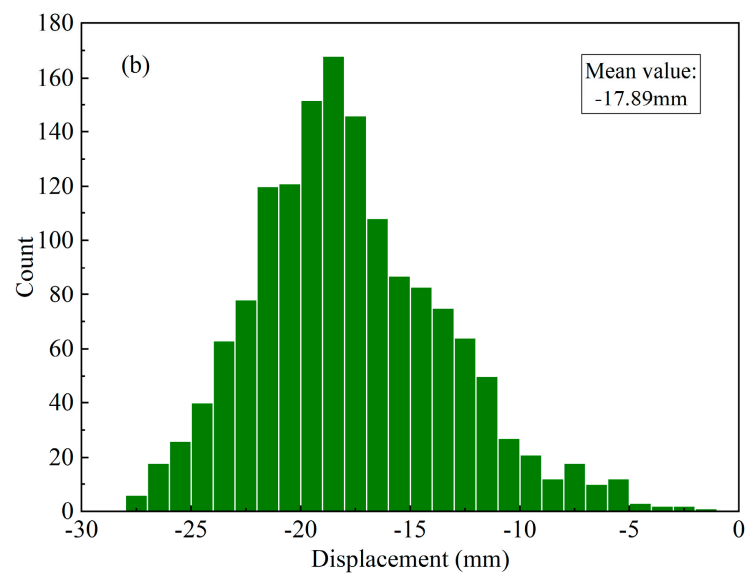

(b)

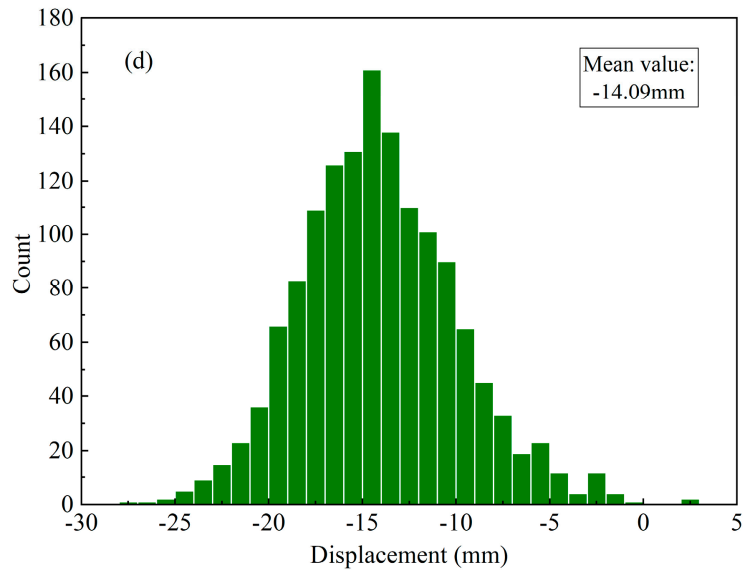

(d)

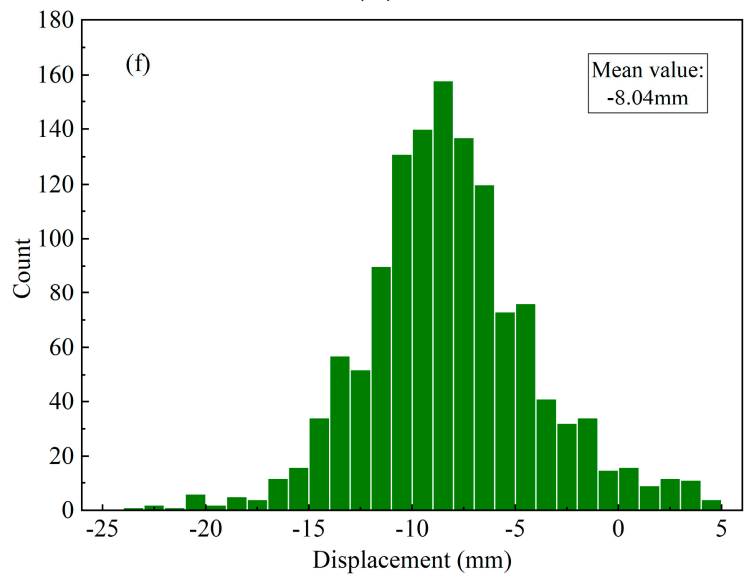

(f)

Figure 8. Cont. 


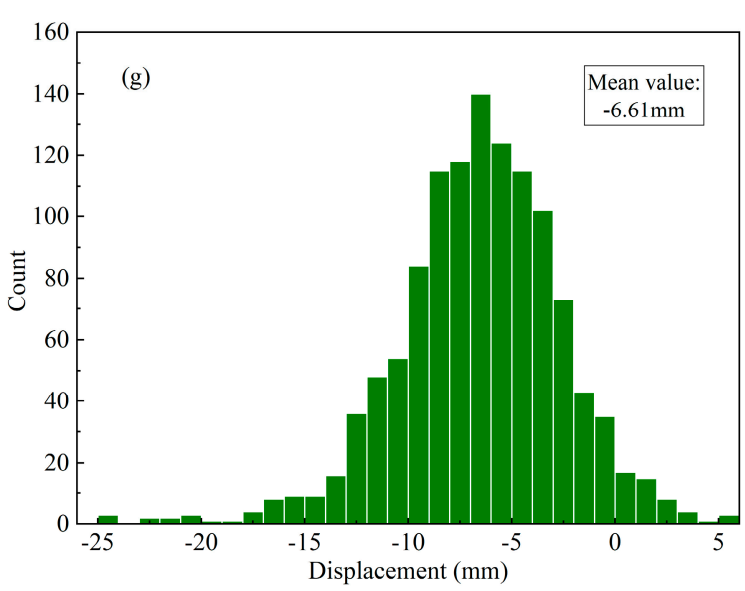

$(\mathrm{g})$

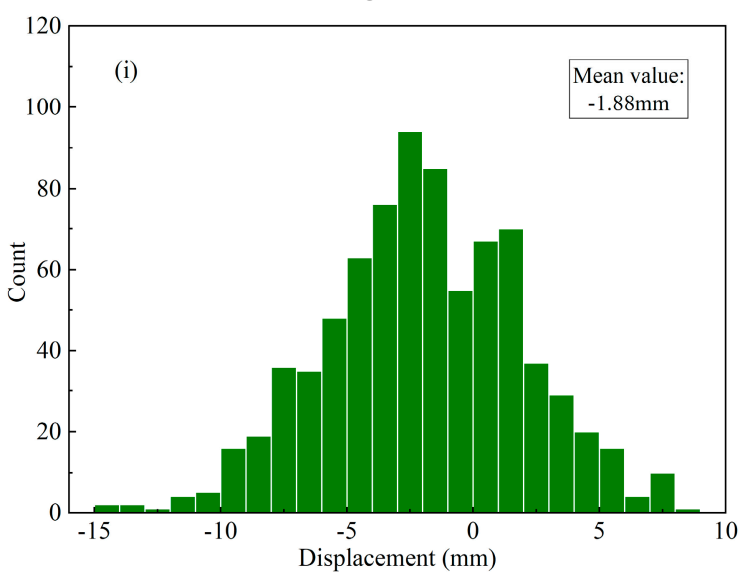

(i)

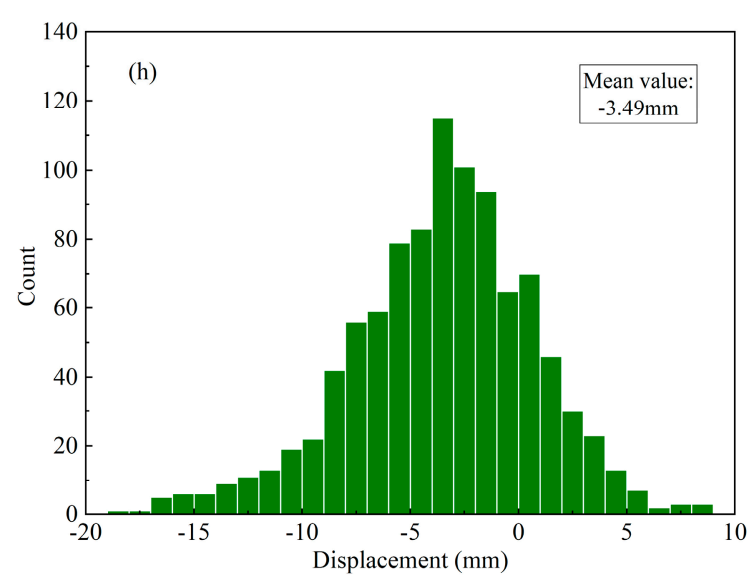

(h)

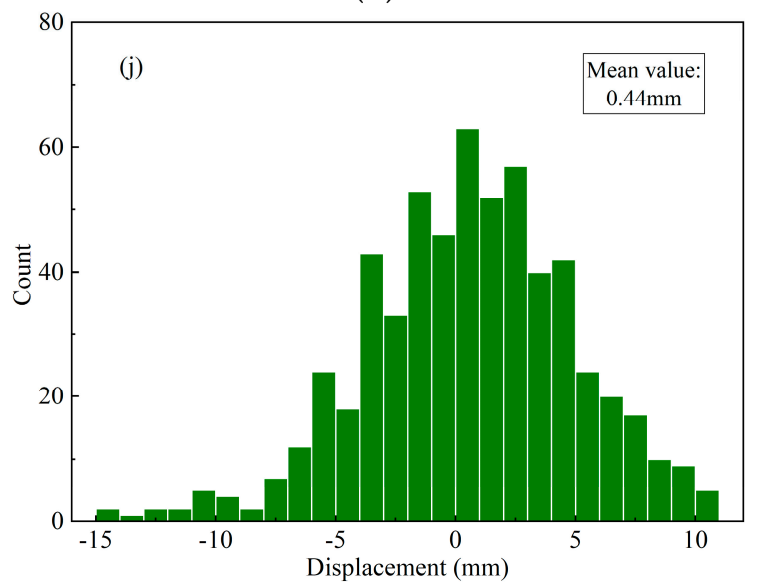

(j)

Figure 8. Statistical histogram of dam surface displacement changes under different elevations. (a) $Z=70.88 \mathrm{~m}$; (b) $Z=63.88 \mathrm{~m}$; (c) $Z=56.88 \mathrm{~m}$; (d) $Z=49.88 \mathrm{~m}$; (e) $Z=42.88 \mathrm{~m}$; (f) $Z=35.88 \mathrm{~m}$; (g) $Z=28.88 \mathrm{~m}$; (h) $Z=21.88 \mathrm{~m}$; (i) $Z=14.88 \mathrm{~m}$; and (j) $Z=7.88 \mathrm{~m}$.

\subsubsection{Analysis of Dam Surface Displacement Variation}

In the experiment, the distance between the models was calculated for all 3891 curve models, and the overall displacement change distribution cloud map of the downstream face of the Xiahuikeng Dam was obtained, as shown in Figure 9a. This figure shows that the point cloud of the dam surface of the second phase has an overall negative displacement change (i.e., toward the upstream direction) relative to the first phase. The displacement change of the dam gradually increases from the base to the crest, and the displacement of the middle part of the dam is higher than that of the left and right sides, as shown in Figure 9 a,c. Since the water level in the reservoir area was higher during the first phase of data collection, the hydrostatic pressure on the middle of the dam will increase as the water level increases, and the pressure on both sides will gradually decrease. Therefore, the analysis results of the dam displacement change appear to describe the real situation accurately. Figure $9 \mathrm{~b}$ shows a statistical histogram of the dam surface displacement changes in the two periods. The abscissa is the dam displacement change, and the ordinate is the number of point clouds in the interval of different displacement changes. The Gaussian distribution curve is calculated using the statistical histogram, and the interval under the $95 \%$ confidence level is the real displacement change in the dam, which is primarily concentrated between $-28 \mathrm{~mm}$ and $-4 \mathrm{~mm}$. Figure $9 \mathrm{c}$ shows the displacement changes in the left, right and middle parts of the dam with different elevations. 

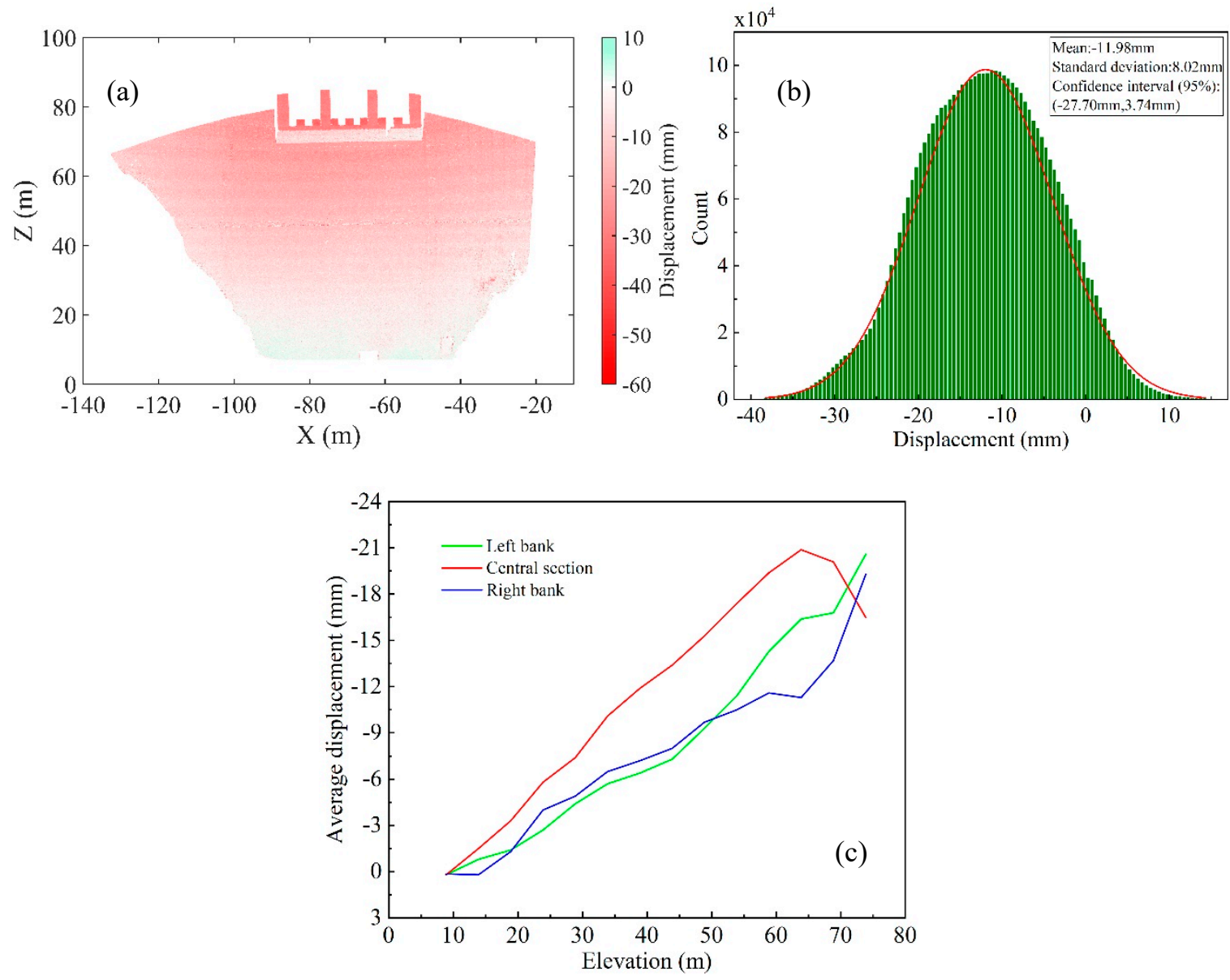

Figure 9. Results of dam displacement variation by contour curve model to model. (a) Cloud map of dam displacement variation distribution; (b) statistical histogram of displacement changes; and (c) average displacement changes of different parts of the dam with different elevations.

\section{Discussion}

This study investigates the dam displacement change detection method using groundbased 3D laser point clouds, two-step registration of the rock mass, and a comparison of distances using a contour curve model. The two-step registration method uses the ICP algorithm to quickly and roughly register the two states of the complete point cloud and uses the result as the initial value to achieve secondary accurate registration of the stable rock mass point cloud in front of the dam. This method replaces evenly distributed rock masses with manual targets and corresponding lines to describe point cloud registration from the entire dam to specific areas on the dam and from rough to fine resolutions. The proposed method is suitable for natural scenes without control nets and corresponding targets that lack linear and planar features. However, to ensure the quality of registration, we use simple feature thresholds to remove a large amount of vegetation and then manually remove weeds and noise points that are attached to the surface of the rock mass to obtain a pure rock mass point cloud. The classification of rock masses is not automated; therefore, future research should investigate the automatic classification of rock mass point clouds.

By establishing a contour curve model of the arch dam surface and comparing the distance between the two models, the dam surface displacement changes in the two states are detected and described. Compared to the point-to-model comparison, the model-tomodel comparison can reduce the impact of point cloud roughness on the accuracy of point cloud distance calculation. The contour curve model construction method is simple and flexible and is thus suitable for a comparison of the overall and local displacement of the arch dam surface with varying curvatures. 
To verify the effectiveness of a comparison method further, we used two mainstream distance comparison methods that are referred to as point cloud to point cloud (C2C) and point cloud to TIN (Triangulated Irregular Network) model (C2T) using Cloudcompare software (http:/ / www.cloudcompare.org )accessed on 18 March 2021. Using these methods, the displacement change in the same set of experimental data was calculated. C2C uses the principle of the nearest neighbor algorithm to calculate the distance between two points. For each point in the first group of point clouds, the closest point in the second group of point clouds is identified, and the Euclidean distance between them is calculated. This method does not require processing the data using gridding, resampling, or normal calculation, and has a high calculation efficiency; however, it is sensitive to the roughness of the point cloud and is suitable for rapid change monitoring of dense point clouds. The C2T distance is the distance between the calculated point cloud and the reference model developed by the Delaunay triangulation network. Since the distance between the point and the fitting surface is used instead of the distance between the points, this method is more effective and accurate. The calculation results of the $\mathrm{C} 2 \mathrm{C}$ and $\mathrm{C} 2 \mathrm{~T}$ methods are shown in Figures 10 and 11.
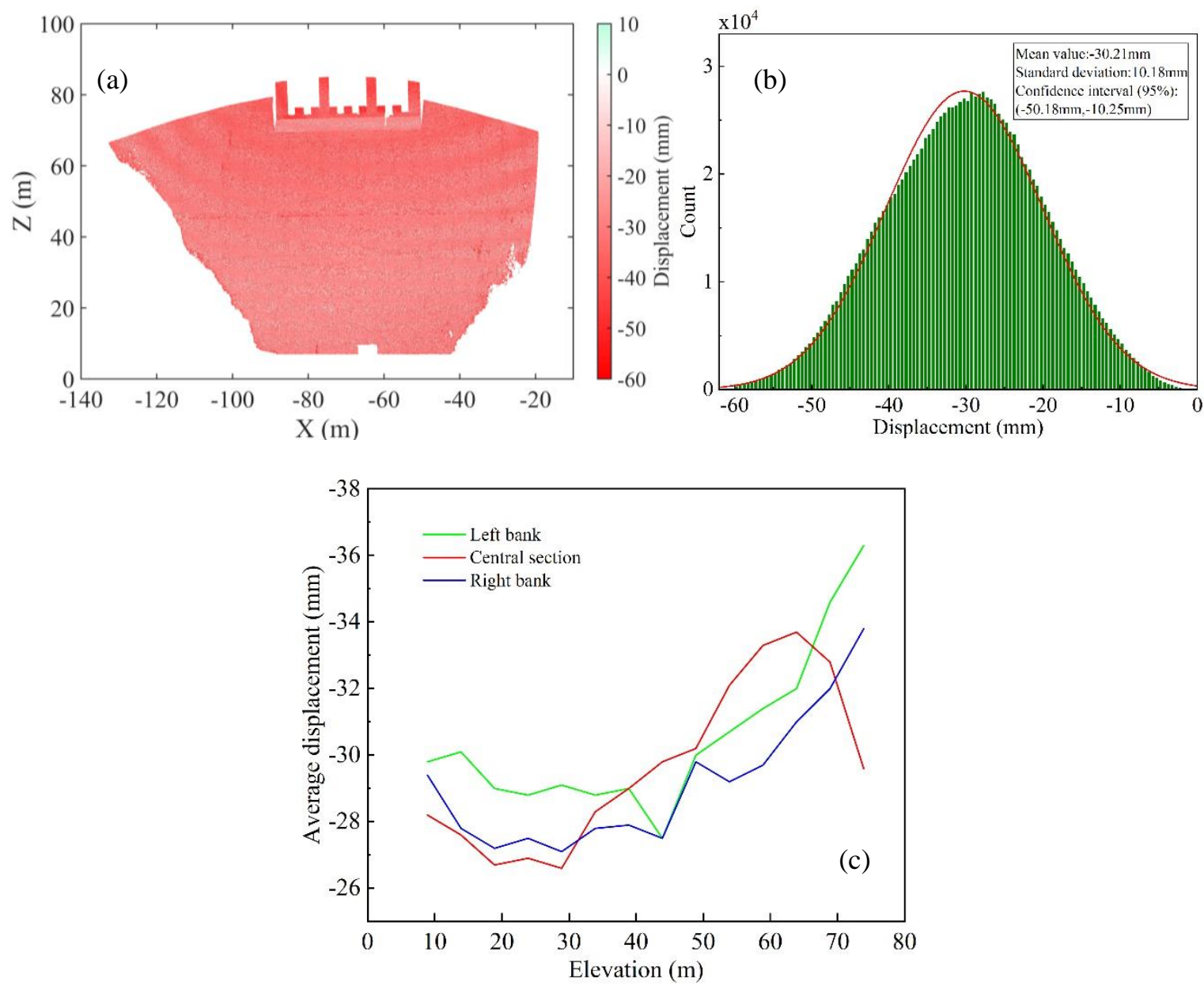

Figure 10. Results of dam displacement changes by point cloud to point cloud (C2C). (a) Cloud map of dam displacement variation distribution; (b) statistical histogram of displacement changes; and (c) average displacement changes of different parts of the dam with different elevations. 

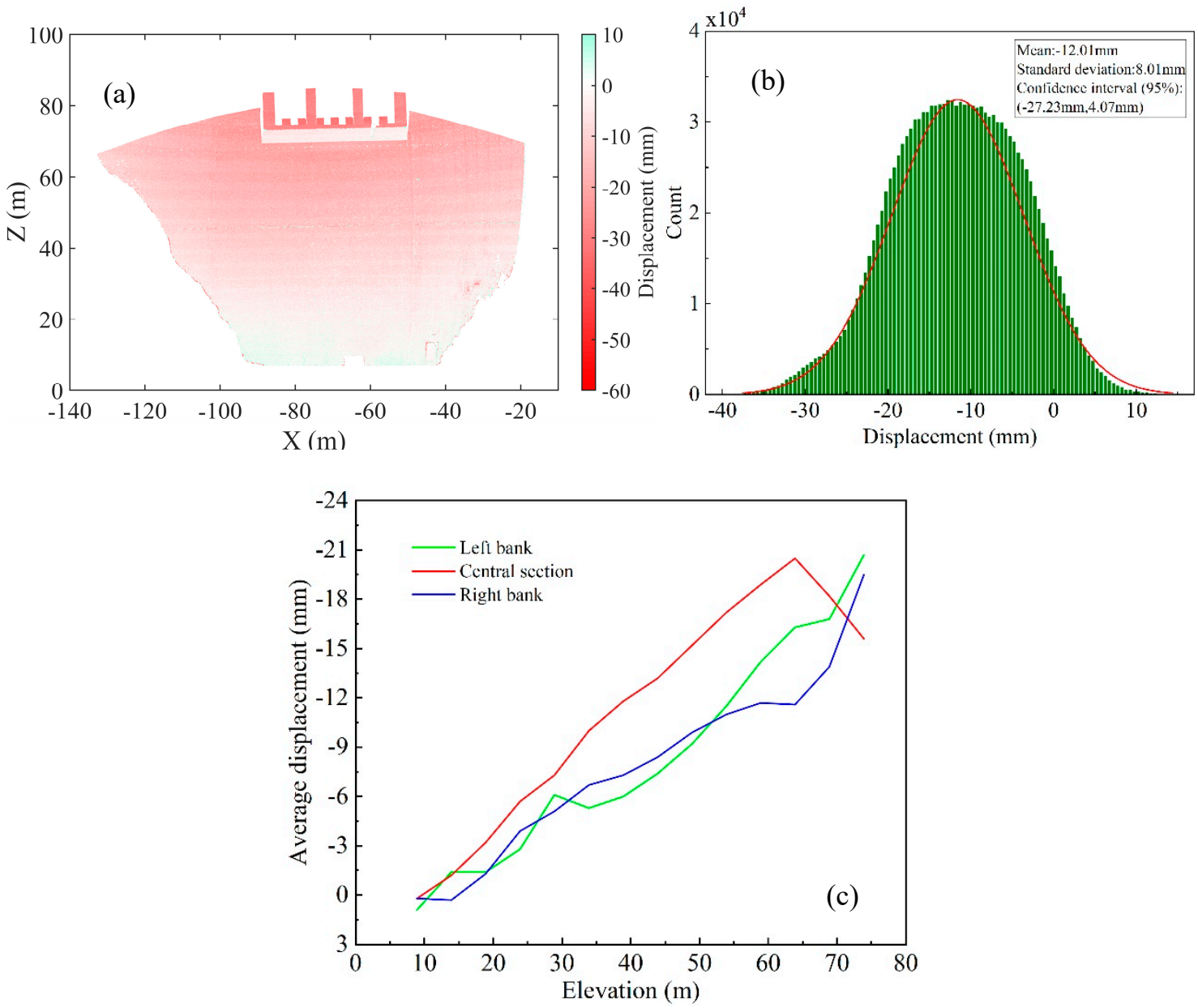

Figure 11. Results of dam displacement changes by point cloud to TIN model (C2T). (a) Cloud map of dam displacement variation distribution; (b) statistical histogram of displacement changes; and (c) average displacement changes of different parts of the dam with different elevations.

A comparison of these results shows that the dam displacement changes obtained by the contour model comparison method proposed in this paper are more consistent with the results of the C2T method, and the observed changes are shown to be concentrated between $-4 \mathrm{~mm}$ and $-28 \mathrm{~mm}$ (Figures $9 \mathrm{~b}$ and $11 \mathrm{~b}$ ). As the elevation increases, the displacement steadily increases in the distribution characteristics, and even the line graph of the displacement of the middle and left bank of the dam by the contour model comparison method is smoother than that of $\mathrm{C} 2 \mathrm{~T}$ (Figures $9 \mathrm{c}$ and $11 \mathrm{c}$ ). The $\mathrm{C} 2 \mathrm{C}$ algorithm calculates that the average displacement changes in the middle of the dam and on both sides of the dam do not exhibit any displacement law (Figure 10c). The changes are large, scattered, and are primarily between $10 \mathrm{~mm}$ and $50 \mathrm{~mm}$ (Figure 10a,b). The method proposed in this paper constructs a contour model for the two-phase point cloud, replacing the distance between the scattered point clouds and the distance between the models, which markedly reduces the influence of the point cloud roughness on the calculation of the deformation value compared to $\mathrm{C} 2 \mathrm{C}$. This method does not require complete data modeling and is more flexible and efficient for analyzing and monitoring local elevation deformation.

\section{Conclusions}

In this paper, the arch dam displacement change detection method based on a 3D laser point cloud is studied. The two-step registration method from rough to fine is proposed by using the corresponding rock point clouds instead of the point, line, and plane, which is suitable for natural scenes around the dam. This method can reduce the time and economic cost of field measurement in conjunction with other equipment, and at the same time, 
solve the problem that the artificial target cannot be stored in the field for a long time. Then, a simple and flexible curve contour is used for the model-to-model point cloud comparison for the arch dam to eliminate the influence of point cloud roughness on the comparison accuracy. Curve fitting is simpler than surface fitting, which is not affected by missing data, and it is easier to describe arch dam surfaces with different curvatures.

Considering the Xiahuikeng Arch Dam in the Shangrao area of Jiangxi Province, China, as a test subject, the point clouds on the downstream surface of the dam are registered for two periods of data, and then the local and overall displacement changes from the contour model to the model are analyzed. Results show that the above method is effective in the displacement detection of arch dams and provides a feasible solution for dam deformation analysis using 3D laser technology.

Author Contributions: Conceptualization, Yijing Li and Ping Liu; data curation, Ping Liu; formal analysis, Huokun Li; funding acquisition, Huokun Li, Faming Huang, Yijing Li; investigation, Huokun Li; methodology, Yijing Li and Ping Liu; project administration, Yijing Li and Huokun Li; Resources, Yijing Li; software, Ping Liu; supervision, Huokun Li; validation, Faming Huang; writing - original draft preparation, Ping Liu and Yijing Li.; writing-review and editing, Ping Liu, Yijing Li, Faming Huang and Huokun Li. All authors have read and agreed to the published version of the manuscript.

Funding: This research is funded by the Natural Science Foundation of China (No. 51879126, 52079061, 41807285), the Jiangxi Provincial Water Resources Department Science and Technology Foundation (No. KT201544).

Data Availability Statement: Data sharing not applicable.

Acknowledgments: Thanks to Shangrao Hydraulic Reasarch Institute for providing experimental objects for this paper.

Conflicts of Interest: The authors declare no conflict of interest.

\section{References}

1. Reyes-Carmona, C.; Barra, A.; Galve, J.P.; Monserrat, O.; Pérez-Peña, J.V.; Mateos, R.M.; Notti, D.; Ruano, P.; Millares, A.; López-Vinielles, J. Sentinel-1 Dinsar for monitoring active landslides in critical infrastructures: The case of the rules reservoir (Southern Spain). Remote Sens. 2020, 12, 809. [CrossRef]

2. Hamzic, A.; Avdagic, Z.; Besic, I. Multistage cascade predictor of structural elements movement in the deformation analysis of large objects based on time series influencing factors. ISPRS Int. J. Geo-Inf. 2020, 9, 47. [CrossRef]

3. Li, Y.; Huang, J.; Jiang, S.-H.; Huang, F.; Chang, Z. A web-based gps system for displacement monitoring and failure mechanism analysis of reservoir landslide. Sci. Rep. 2017, 7, 17171. [CrossRef] [PubMed]

4. Huang, F.; Wu, P.; Ziggah, Y. Gps monitoring landslide deformation signal processing using time-series model. Int. J. Signal Process. Image Process. Pattern Recognit. 2016, 9, 321-332. [CrossRef]

5. Huang, F.; Chen, J.; Du, Z.; Yao, C.; Huang, J.; Jiang, Q.; Chang, Z.; Li, S. Landslide susceptibility prediction considering regional soil erosion based on machine-learning models. ISPRS Int. J. Geo-Inf. 2020, 9, 377. [CrossRef]

6. Chao, Z.; Kun-long, Y.; HUANG, F.-M. Application of the chaotic sequence wa-elm coupling model in landslide displacement prediction. Rock Soil Mech. 2015, 36, 2674-2680.

7. Huang, F.; Huang, J.; Jiang, S.; Zhou, C. Landslide displacement prediction based on multivariate chaotic model and extreme learning machine. Eng. Geol. 2017, 218, 173-186. [CrossRef]

8. Zhu, L.; Wang, G.; Huang, F.; Li, Y.; Hong, H. Landslide susceptibility prediction using sparse feature extraction and machine learning models based on gis and remote sensing. IEEE Geosci. Remote Sens. Lett. 2021, 1-5. [CrossRef]

9. Huang, F.; Cao, Z.; Guo, J.; Jiang, S.-H.; Li, S.; Guo, Z. Comparisons of heuristic, general statistical and machine learning models for landslide susceptibility prediction and mapping. Catena 2020, 191, 104580. [CrossRef]

10. Huang, F.; Tian, Y. Wa-volterra coupling model based on chaos theory for monthly precipitation forecasting. Earth Sci. J. China Univ. Geosci. 2014, 34, 368-374.

11. Milillo, P.; Perissin, D.; Salzer, J.T.; Lundgren, P.; Lacava, G.; Milillo, G.; Serio, C. Monitoring dam structural health from space: Insights from novel insar techniques and multi-parametric modeling applied to the pertusillo dam basilicata, Italy. Int. J. Appl. Earth Obs. Geoinf. 2016, 52, 221-229. [CrossRef]

12. Wang, T.; Perissin, D.; Rocca, F.; Liao, M.-S. Three gorges dam stability monitoring with time-series insar image analysis. Sci. China Earth Sci. 2011, 54, 720-732. [CrossRef]

13. Bin, L.; Daqing, G.; Man, L.; Ling, Z.; Yan, W.; Xiaofang, G.; Xiaobo, Z. Ground-based interferometric synthetic aperture radar and its applications. Remote Sens. Land Resour. 2017, 29, 1-6. 
14. Pieraccini, M. Monitoring of civil infrastructures by interferometric radar: A review. Sci. World J. 2013, 2013, 786961. [CrossRef] [PubMed]

15. Del Ventisette, C.; Casagli, N.; Fortuny-Guasch, J.; Tarchi, D. Ruinon landslide (valfurva, italy) activity in relation to rainfall by means of gbinsar monitoring. Landslides 2012, 9, 497-509. [CrossRef]

16. Mao, W.-J.; Chang, W.-l. Deformation monitoring by ground-based sar interferometry (gb-insar): A field test in dam. Adv. Inf. Sci. Serv. Sci. 2015, 7, 133.

17. Changjun, L.; Yu, Z.; Changfeng, Y. Study of the key tech-nologies for mine rapid topographic survey based on $3 d$ laser meas-urement. Bull. Surv. Mapp. 2012, 6, 43-46.

18. Deng, Y.; Yu, K.; Yao, X.; Xie, Q.; Hsieh, Y.; Liu, J. Estimation of pinus massoniana leaf area using terrestrial laser scanning. Forests 2019, 10, 660. [CrossRef]

19. Lin, Y.; Hyyppä, J.; Kukko, A.; Jaakkola, A.; Kaartinen, H. Tree height growth measurement with single-scan airborne, static terrestrial and mobile laser scanning. Sensors 2012, 12, 12798-12813. [CrossRef]

20. Huang, F.; Yang, J.; Zhang, B.; Li, Y.; Huang, J.; Chen, N. Regional terrain complexity assessment based on principal component analysis and geographic information system: A case of jiangxi province, China. ISPRS Int. J. Geo-Inf. 2020, 9, 539. [CrossRef]

21. Huang, F.; Zhang, J.; Zhou, C.; Wang, Y.; Huang, J.; Zhu, L. A deep learning algorithm using a fully connected sparse autoencoder neural network for landslide susceptibility prediction. Landslides 2020, 17, 217-229. [CrossRef]

22. Huang, F.; Yin, K.; Huang, J.; Gui, L.; Wang, P. Landslide susceptibility mapping based on self-organizing-map network and extreme learning machine. Eng. Geol. 2017, 223, 11-22. [CrossRef]

23. Chang, Z.; Du, Z.; Zhang, F.; Huang, F.; Chen, J.; Li, W.; Guo, Z. Landslide susceptibility prediction based on remote sensing images and gis: Comparisons of supervised and unsupervised machine learning models. Remote Sens. 2020, 12, 502. [CrossRef]

24. Huang, F.; Ye, Z.; Jiang, S.-H.; Huang, J.; Chang, Z.; Chen, J. Uncertainty study of landslide susceptibility prediction considering the different attribute interval numbers of environmental factors and different data-based models. CATENA 2021, 202, 105250. [CrossRef]

25. Huang, F.; Yin, K.; Zhang, G.; Zhou, C.; Zhang, J. Landslide groundwater level time series prediction based on phase space reconstruction and wavelet analysis-support vector machine optimized by pso algorithm. Earth Sci. J. China Univ. Geosci. 2015, 40, 1254-1265.

26. Dai, H.; Lian, X.; Chen, Y.; Cai, Y.; Liu, Y. Study of the deformation of houses induce by mining based on 3d laser scanning. Bull. Surv. Mapp. 2011, 11, 44-46.

27. Tuo, L.; Kang, Z.; Xie, Y.; Wang, B. Continuously vertical section abstraction for deformation monitoring of subway tunnel based on terrestrial point clouds. Geomat. Inf. Sci. Wuhan Univ. 2013, 38, 171-175.

28. Hongyi, C.; Xiaobin, H.; Chongrui, L. Application of terrestrial 3D laser scanning technology in deformation monitoring. Bull. Surv. Mapp. 2014, 74. [CrossRef]

29. Huang, F.; Cao, Z.; Jiang, S.-H.; Zhou, C.; Huang, J.; Guo, Z. Landslide susceptibility prediction based on a semi-supervised multiple-layer perceptron model. Landslides 2020, 17, 2919-2930. [CrossRef]

30. Bonneau, D.; DiFrancesco, P.-M.; Hutchinson, D.J. Surface reconstruction for three-dimensional rockfall volumetric analysis. ISPRS Int. J. Geo-Inf. 2019, 8, 548. [CrossRef]

31. Colaço, A.F.; Trevisan, R.G.; Molin, J.P.; Rosell-Polo, J.R. A method to obtain orange crop geometry information using a mobile terrestrial laser scanner and 3d modeling. Remote Sens. 2017, 9, 763. [CrossRef]

32. Erdélyi, J.; Kopáčik, A.; Kyrinovič, P. Spatial data analysis for deformation monitoring of bridge structures. Appl. Sci. 2020, 10, 8731. [CrossRef]

33. Cheng, Y.-J.; Qiu, W.; Lei, J. Automatic extraction of tunnel lining cross-sections from terrestrial laser scanning point clouds. Sensors 2016, 16, 1648. [CrossRef] [PubMed]

34. Ma, X.; Wang, L.; Chen, C.; Du, J.; Sun, S. Simulation of the dynamic water storage and its gravitational effect in the head region of three gorges reservoir using imageries of gaofen-1. Remote Sens. 2020, 12, 3353. [CrossRef]

35. F Gama, F.; Mura, J.C.; R Paradella, W.; G de Oliveira, C. Deformations prior to the brumadinho dam collapse revealed by sentinel-1 insar data using sbas and psi techniques. Remote Sens. 2020, 12, 3664. [CrossRef]

36. Sun, H.; Xu, Z.; Yao, L.; Zhong, R.; Du, L.; Wu, H. Tunnel monitoring and measuring system using mobile laser scanning: Design and deployment. Remote Sens. 2020, 12, 730. [CrossRef]

37. Zhi-yong, W.; Yao-ying, H.; Xin-rui, Z.; Quan-yu, Z.; Xiang-hong, L. Application of three-dimensional laser scanning technique in deformation monitoring of extrusion sidewall of concrete-faced rockfill dam. J. Yangtze River Sci. Res. Inst. 2017, $34,56$.

38. Guo, C. Data Processing and Application of 3D Laser Scanning to Dam Subsidence Monitoring in Mining Area. Master's Thesis, Jilin University, Changchun, China, 2014.

39. Wang, J.; Zhang, C. Deformation monitoring of earth-rock dams based on three-dimensional laser scanning technology. Chin. J. Geotech. Eng. 2014, 36, 2345-2350. [CrossRef]

40. Xu, J.; Wang, H.; Luo, Y.; Wang, S.-Q.; Yan, X.-Q. Deformation monitoring and data processing of landslide based on 3D laser scanning. Rock Soil Mech. 2010, 31, 2188-2191.

41. Wang, J.; Wang, D.; Liu, S.; Jia, B. Delineating minor landslide displacements using gps and terrestrial laser scanning-derived terrain surfaces and trees: A case study of the slumgullion landslide, lake city, colorado. Surv. Rev. 2018, 52, 215-223. [CrossRef] 
42. Li, L.; Cao, X.; He, Q.; Sun, J.; Jia, B.; Dong, X. A new 3D laser-scanning and gps combined measurement system. C. R. Geosci. 2019, 351, 508-516. [CrossRef]

43. Huang, F.; Yin, K.; He, T.; Zhou, C.; Zhang, J. Influencing factor analysis and displacement prediction in reservoir landslidesA case study of three gorges reservoir (China). Teh. Vjesn. 2016, 23, 617-626.

44. Guo, Z.; Yin, K.; Gui, L.; Liu, Q.; Huang, F.; Wang, T. Regional rainfall warning system for landslides with creep deformation in three gorges using a statistical black box model. Sci. Rep. 2019, 9, 8962. [CrossRef]

45. Liu, W.; Luo, X.; Huang, F.; Fu, M. Uncertainty of the soil-water characteristic curve and its effects on slope seepage and stability analysis under conditions of rainfall using the markov chain monte carlo method. Water 2017, 9, 758. [CrossRef]

46. Liu, W.; Luo, X.; Huang, F.; Fu, M. Prediction of soil water retention curve using bayesian updating from limited measurement data. Appl. Math. Model. 2019, 76, 380-395. [CrossRef]

47. Xie, X.; Lu, X. Development of a 3d modeling algorithm for tunnel deformation monitoring based on terrestrial laser scanning. Undergr. Space 2017, 2, 16-29. [CrossRef]

48. Depeng, Y.; Jiping, W.; Jinxing, Z.; Xiaoxue, C.; Huijun, R. Monitoring slope deformation using a 3-d laser image scanning system: A case study. Min. Sci. Technol. (China) 2010, 20, 898-903.

49. Ji, Z.; Song, M.; Guan, H.; Yu, Y. Accurate and robust registration of high-speed railway viaduct point clouds using closing conditions and external geometric constraints. Isprs J. Photogramm. Remote Sens. 2015, 106, 55-67. [CrossRef]

50. Tan, K.; Zhang, W.; Shen, F.; Cheng, X. Investigation of tls intensity data and distance measurement errors from target specular reflections. Remote Sens. 2018, 10, 1077. [CrossRef]

51. Chen, L.-C.; Teo, T.-A.; Rau, J.-Y.; Liu, J.-K.; Hsu, W.-C. Building reconstruction from lidar data and aerial imagery. In Proceedings of the 2005 IEEE International Geoscience and Remote Sensing Symposium, 2005, IGARSS'05, Seoul, Korea, 29 July 2005 ; IEEE: Piscataway, NJ, USA, 2005; pp. 2846-2849.

52. $\mathrm{Xu}, \mathrm{J} . ;$ Wang, J. Auto-registration method of ground based building point clouds based on line features and iterative closest point algorithm. J. Comput. Appl. 2020, 40, 1837-1841.

53. Date, H.; Wakisaka, E.; Moribe, Y.; Kanai, S. Tls point cloud registration based on icp algorithm using point quality. Int. Arch. Photogramm. Remote Sens. Spat. Inf. Sci. 2019, XLII-2/W13, 963-968. [CrossRef]

54. Li, Y.; Junxiang, T.; Hua, L.; Changjun, C. Registration of tls and mls point cloud combining genetic algorithm with icp. Acta Geod. Et Cartogr. Sin. 2018, 47, 528.

55. Zhu, L.; Huang, L.; Fan, L.; Huang, J.; Huang, F.; Chen, J.; Zhang, Z.; Wang, Y. Landslide susceptibility prediction modeling based on remote sensing and a novel deep learning algorithm of a cascade-parallel recurrent neural network. Sensors 2020, 20, 1576 [CrossRef]

56. Lague, D.; Brodu, N.; Leroux, J. Accurate 3D comparison of complex topography with terrestrial laser scanner: Application to the rangitikei canyon (N-Z). ISPRS J. Photogramm. Remote Sens. 2013, 82, 10-26. [CrossRef]

57. Abellán, A.; Calvet, J.; Vilaplana, J.M.; Blanchard, J. Detection and spatial prediction of rockfalls by means of terrestrial laser scanner monitoring. Geomorphology 2010, 119, 162-171. [CrossRef]

58. Huang, F.; Wang, Y.; Dong, Z.; Wu, L.; Guo, Z.; Zhang, T. Regional landslide susceptibility mapping based on grey relational degree model. Earth Sci. 2019, 44, 664-676.

59. Li, D.; Huang, F.; Yan, L.; Cao, Z.; Chen, J.; Ye, Z. Landslide susceptibility prediction using particle-swarm-optimized multilayer perceptron: Comparisons with multilayer-perceptron-only, bp neural network, and information value models. Appl. Sci. 2019, 9, 3664. [CrossRef]

60. Girardeau-Montaut, D.; Roux, M.; Marc, R.; Thibault, G. Change detection on points cloud data acquired with a ground laser scanner. Int. Arch. Photogramm. Remote Sens. Spat. Inf. Sci. 2005, 36, W19.

61. Xu, H.; Li, H.; Yang, X.; Qi, S.; Zhou, J. Integration of terrestrial laser scanning and nurbs modeling for the deformation monitoring of an earth-rock dam. Sensors 2019, 19, 22. [CrossRef]

62. Monserrat, O.; Crosetto, M. Deformation measurement using terrestrial laser scanning data and least squares $3 \mathrm{~d}$ surface matching. ISPRS J. Photogramm. Remote Sens. 2008, 63, 142-154. [CrossRef]

63. Van Gosliga, R.; Lindenbergh, R.; Pfeifer, N. Deformation Analysis of a Bored Tunnel by Means of Terrestrial Laser Scanning. 2006. Available online: https://www.researchgate.net/profile/Norbert-Pfeifer-3/publication/228940110_Deformation_analysis_of_ a_bored_tunnel_by_means_of_terrestrial_laser_scanning/links / Ofcfd509bb2693f92e000000/Deformation-analysis-of-a-boredtunnel-by-means-of-terrestrial-laser-scanning.pdf (accessed on 18 March 2021).

64. Xu, X.; Yang, H.; Kargoll, B. Robust and automatic modeling of tunnel structures based on terrestrial laser scanning measurement. Int. J. Distrib. Sens. Netw. 2019, 15, 1550147719884886. [CrossRef]

65. Alba, M.; Fregonese, L.; Prandi, F.; Scaioni, M.; Valgoi, P. Structural monitoring of a large dam by terrestrial laser scanning. Int. Arch. Photogramm. Remote Sens. Spat. Inf. Sci. 2006, 36, 6.

66. Qi, J.; Shou, H. A subdivision algorithm for computing the minimum distance between a point and an algebraic curve. J. Zhejiang Univ. (Sci. Ed.) 2016, 43, 03. 